\title{
Apoptosis Induction Effect of Three Jujube Cultivars in HepG2 and Jurkat Cell Lines
}

\author{
Natthanan Taechakulwanijya, Natthida Weerapreeyakul, Sahapat Barusrux, and Sirithorn Siriamornpun
}

\begin{abstract}
The potential cancer preventive effects of water and ethanolic extracts of three new jujube cultivars were examined in HepG2 and Jurkat cancer cell lines. Apoptosis induction was detected from alteration of nuclei morphology via DAPI staining, and apoptosis death mode was detected via Annexin V-FITC and propidium iodide fluorescence flow cytometry. Results showed that ethanolic jujube seed extracts exhibited antiproliferation only in the Jurkat cell line. Cultivar Taiwan exerted high antiproliferation effect $\left(\mathrm{IC}_{\mathbf{5 0}}=\mathbf{2 3 2 . 4} \pm \mathbf{7 . 8}\right.$ $\mu \mathrm{g} / \mathrm{ml})>$ Jumbo $\left(\mathrm{IC}_{50}=312.0 \pm 18.3 \mu \mathrm{g} / \mathrm{ml}\right)>$ Rianthong $\left(\mathrm{IC}_{50}=401.6 \pm 9.9 \mu \mathrm{g} / \mathrm{ml}\right)$, respectively $(p<0.05)$. Melphalan (a positive control) exhibited significant antiproliferation in both HepG2 $\left(\mathrm{IC}_{50}=37.5 \pm 3.9 \mu \mathrm{g} / \mathrm{ml}\right)$, and Jurkat cell lines $\left(\mathrm{IC}_{50}=119.1 \pm 10.4 \mu \mathrm{g} / \mathrm{ml}\right)$ but also had cytotoxic effect on the normal Vero cell line $\left(\mathrm{IC}_{50}=\mathbf{7 5 . 0} \pm \mathbf{2 . 3} \boldsymbol{\mu \mathrm { g }} / \mathrm{ml}\right)$. The early and late stages of apoptotic cell death as well as necrosis were detected in Jurkat cells, in both a cultivar and a concentration dependent manner. Jumbo induced more late stage apoptosis > Rianthong $>$ Taiwan $>$ melphalan. The order of test compounds that caused necrosis were Taiwan $>$ Jumbo > Rianthong > melphalan. Rianthong was the most promising cancer preventive cultivar based on antiproliferation and apoptosis induction activity with corresponding less necrosis. However, as all jujube seed extracts were not toxic to Vero cells, all jujubes cultivars tested are promising candidates for more elaborate study of their anticancer mechanisms.
\end{abstract}

Index Terms-Apoptosis, jujube, cytotoxicity, cancer.

\section{INTRODUCTION}

Jujubes came from two major genuses which are Ziziphus mauritiana Lam. and Ziziphus jujuba Mill [1]. Jujube belong to RHAMNACEAE family. It has long been recognized as an edible fruit [2]. In addition, various parts of jujubes were reported to be useful for treatment of many symptoms and diseases, for example; diabetes (96\% ethanolic extract of $Z$. jujuba leaves) [3], diarrhea (methanolic extract of $Z$. mauritiana roots) [4], inhibition of hepatic lipid peroxidation

Manuscript received April 19, 2013; revised June 19, 2013. This work was supported by the Thai research Fund Grant RDG5420072.

Natthanan Taechakulwanijya is with the Graduate School, Faculty of Pharmaceutical Sciences, Khon Kaen University, Khon Kaen, 40002, Thailand. (e-mail: natthanan.taechakulwanijya@gmail.com).

Natthida Weerapreeyakul is with Center for Research and Development of Herbal Health Products (CRD-HHP), Faculty of Pharmaceutical Sciences, Khon Kaen, University, Khon Kaen, 40002, Thailand (e-mail: natthida@kku.ac.th).

Sahapat Barusrux is with Centre for Research and Development of Medical Diagnostic Laboratories (CMDL), Faculty of Associated Medical Sciences, Khon Kaen University, Khon Kaen, 40002, Thailand (e-mail: sahapat@kku.ac.th).

Sirithorn Siriamornpun is with Department of Food Technology and Nutrition, Mahasarakham University, Mahasarakham, 44150, Thailand (e-mail: sirithons@hotmail.com). (aqueous extract of Z. mauritania leaves) [5], anti-fungal activity (ethanolic extract of $Z$. jujuba stone) [6] enhancing choline acetyltransferase associated with Alzheimer's disease (methanolic extract of $Z$. jujuba fruits) [7], anxiolytic effect (methanolic extract of Z. jujuba seed) [8], and enhanced permeability in cell culture monolayer (aqueous extract of Z. jujuba seed) [9]. The active compounds found in jujube were triterpeonic acid (roots) [10], 6"'-feruloylspinosin, 6"'-sinapoylspinosin, jujuboside A, B (seeds) [11], linoleic, oleic and stearic acids (seeds) [12]. Previously, Ziziphus species were reported to induce apoptosis programmed cell death in many cancer cell lines [13]-[15] and in tumor cells of Swiss albino mice [13].

Cancer is the severe chronic disease that is found worldwide with increasingly high rate of morbidity and mortality [16]. Therefore, it is of interest to search for cancer preventive agent from natural source. One preferable pharmacodynamic endpoint for cancer treatment is via inducing apoptotic cell death [17]. Hence, apoptosis induction is the primary goal of chemotherapy. Apoptosis is the cell mechanism that balances between cancer cell proliferation and damage irreparable cell including damage DNA. Then, dead cells are phagocytosed by macrophages. The advantage of this death mode does not lead to inflammation in neighboring cells as same as necrosis [17].

According to the reports of biological activity of jujubes and new cultivars of Thai jujubes have been cross-bred, this study was aimed to investigate the apoptosis induction effect of the jujube seed extract of three jujube cultivars (i.e., Rianthong, Jumbo and Taiwan) against the human hepatocellular carcinoma HepG2 and human leukemic Jurkat cell lines compared to the normal African green monkey kidney Vero cells.

\section{MATERIALS AND METHODS}

\section{A. Plant Materials and Reagents}

The jujube fruits cultivars Rianthong (R), Taiwan (T) and Jumbo (J) were purchased from local markets in Khon Kaen, Thailand in 2012. The Jumbo and Taiwan cultivars are the result of a cross between Z. mauritiana and Z. jujuba, but cultivar (Rianthong) remains unidentified. The cell culture media and fetal bovine serum were purchased from GIBCO, Invitrogen Corporation (USA.). Neutral red dye was purchased from Sigma Chemicals Co. (USA), and melphalan (mel; an apoptosis induction positive control) was bought from Sigma-Aldrich Chemie GmbH (Germany). Apoptotic detection kit was bought from eBiosciences (USA). 


\section{B. Preparation of Jujube Seed Extracts}

The ground dry jujube seeds were macerated in deionized water $(1: 3 \mathrm{w}: \mathrm{v})$ overnight. The water filtrate was collected and freeze-drying yielded crude water extract. The left over residue from water extraction was macerated with ethanol. Ethanol was removed by rotary evaporation to yield the ethanolic extract. Percentage yield was calculated and compared to the weight of dry seed. The extracts were stored at $-20^{\circ} \mathrm{C}$.

\section{Cell Culture}

Human hepatocellular carcinoma (HepG2) and African green monkey kidney (Vero) cell lines were cultured in DMEM medium with $10 \%$ fetal bovine serum. The human acute T cells leukemia cell line (Jurkat) was cultured in RPMI medium with $10 \%$ fetal bovine serum. All cells were maintained under $5 \% \mathrm{CO}_{2}$ at $37^{\circ} \mathrm{C}$.

\section{Cell Viability Assay}

The cell viability assay was based on neutral red (NR) uptake [18]. The cationic NR dye penetrates cell membranes and binds in the lysosomal matrix of viable cells. After washing and fixation, the NR can be detected by spectrophotometer [19]. Briefly, Vero cells at $3 \times 10^{5}$ cells $/ \mathrm{ml}$ or HepG2 cells at $4 \times 10^{5}$ cells $/ \mathrm{ml}$ or Jurkat at $5 \times 10^{5}$ cells $/ \mathrm{ml}$ were independently seeded into 96 well plates and incubated for $24 \mathrm{~h}$ under $5 \% \mathrm{CO}_{2}$ at $37^{\circ} \mathrm{C}$. Various concentrations of the extracts from each cultivar of jujube seed $(10-500 \mu \mathrm{g} / \mathrm{ml})$ were added to the cells and incubated for $24 \mathrm{~h}$. After washing cells, $100 \mu \mathrm{l}$ of $50 \mu \mathrm{g} / \mathrm{ml} \mathrm{NR}$ was added to each well and plates were incubated for another $2 \mathrm{~h}$. The supernatant was aspirated and $0.33 \% \mathrm{HCl}$ in isopropanol was added. The absorbance of NR was measured at $537 \mathrm{~nm}$ with reference wavelength of $650 \mathrm{~nm}$. The $\mathrm{IC}_{50}$ value was calculated and compared to the untreated cells.

\section{E. Determination of Nuclei Morphological Change}

DAPI or 4',6-diamidino-2-phenylindole is a cell-permeable fluorescent dye which binds to DNA and is commonly used to detect nuclei [20]. When cancer cells undergo apoptosis, the nuclei undergo morphological changes, therefore apoptotic cells stained with DAPI could be identified using fluorescence microscopy. The DAPI staining assay was performed following the method of Machana et al., [21] with minor modification. Jurkat cells $\left(3 \times 10^{5}\right.$ cells $\left./ \mathrm{ml}\right)$ were incubated with $250 \mu \mathrm{g} / \mathrm{ml}$ or $500 \mu \mathrm{g} / \mathrm{ml}$ of jujube seed extracts for $24 \mathrm{~h}$. The cells were fixed with cold methanol for $15 \mathrm{~min}$, and then incubated in the dark with $0.3 \mu \mathrm{g} / \mathrm{ml}$ DAPI for $30 \mathrm{~min}$. Then the supernatant was removed and the cells were mounted in $15 \mu \mathrm{l}$ of PBS: glycerin, 1:1.

\section{F. Flow Cytometric Analysis}

The flow cytometric analysis of modes of cell death was conducted using Annexin V-FITC and propidium iodide (PI) staining. Annexin V-FITC binds phosphatidylserine in the outer membrane, whereas PI binds nuclei in dead cells. Cells positively stained with Annexin V and PI (+/+) are considered to be in the late stages of apoptosis. Annexin $\mathrm{V}$ positive but PI negative cells (+/-) indicate cells in the early stages of apoptosis, while cells not stained with Annexin V but PI positive (-/+) are considered necrotic [22]. The method for this assay was adapted from Nasri et al., with some modification [22]. Briefly, Jurkat cells at $3 \times 10^{5}$ cells $/ \mathrm{ml}$ were treated with the seed extracts at $1 \times \mathrm{IC}_{50}$ and $2 \times \mathrm{IC}_{50}$ concentrations $(400 \mu \mathrm{g} / \mathrm{ml}$ and $800 \mu \mathrm{g} / \mathrm{ml}$ for Rianthong; 300 $\mu \mathrm{g} / \mathrm{ml}$ and $600 \mu \mathrm{g} / \mathrm{ml}$ for Jumbo; and $200 \mu \mathrm{g} / \mathrm{ml}$ and 400 $\mu \mathrm{g} / \mathrm{ml}$ for Taiwan) at different incubation times (12 and $24 \mathrm{~h}$ ). Cells were washed in $200 \mu \mathrm{l} 1 \mathrm{x}$ binding buffer and centrifuged at $1677 \times \mathrm{g}$ for $5 \mathrm{~min}$. Then $5 \mu \mathrm{l}$ Annexin $\mathrm{V}$ in 95 $\mu 1$ binding buffer was added and the cells were incubated for $15 \mathrm{~min}$ at $25^{\circ} \mathrm{C}$. Then $5 \mu 1$ propidium iodide in $95 \mu 1$ binding buffer was added and the cells were incubated for another 15 min. All of the procedure was kept from light. Cells were washed and resuspended with $200 \mu \mathrm{l}$ binding buffer. The cell dot plot was analyzed using flow cytometry (FACSDiva software version 6.1.3).

\section{G. Statistical Analysis}

The data are shown as means \pm standard deviation $(n=3)$. The statistical analysis was performed by using one-way ANOVA test (IBM SPSS Statistic 19) with 95\% confidence interval.

\section{RESUlTS AND DISCUSSION}

\section{A. Antiproliferation}

The \%yield and $\mathrm{IC}_{50}$ values of water $\left(\mathrm{H}_{2} \mathrm{O}\right)$ and ethanolic $(\mathrm{EtOH})$ extracts of jujube seeds from the three cultivars are shown in Table I. The ethanolic extracts of all three jujube cultivars possessed significant cytotoxic effects in the human acute $\mathrm{T}$ cell leukemia cell line (Jurkat, $p<0.001$, one-way ANOVA). Cultivar Taiwan exerted a significantly greater antiproliferation effect than Jumbo and Rianthong, respectively $(p<0.001$, one-way ANOVA). Melphalan exhibited an antiproliferation effect on both cancer cell lines and the non-cancer cell line, Vero. Interestingly, the ethanolic seed extract of all three jujube cultivars did not exert any cytotoxic effect on the normal Vero cell line, indicating the cancer selectivity and safety of ethanolic jujube extracts.

TABLE I: PERCENT YIELD AND ANTIPROLIFERATION REPRESENTED AS THE IC50 VALUES OF JUJUBE SEED EXTRACTS IN VARIOUS CELL LiNES AT 24 HOURS Jujube $\quad \%$ Yield $\quad \mathrm{IC}_{50}(\mu \mathrm{g} / \mathrm{ml})(\mathrm{N}=3)$

\begin{tabular}{|c|c|c|c|c|c|c|c|c|}
\hline \multirow{3}{*}{ Cultivar } & \multirow{2}{*}{\multicolumn{4}{|c|}{ HepG2 }} & \\
\hline & & & & & & & & \\
\hline & $\mathrm{H}_{2} \mathrm{O}$ & $\mathrm{EtOH}$ & $\mathrm{H}_{2} \mathrm{O}$ & $\mathrm{EtOH}$ & $\mathrm{H}_{2} \mathrm{O}$ & $\mathrm{EtOH}$ & $\mathrm{H}_{2} \mathrm{O}$ & $\mathrm{EtOH}$ \\
\hline $\mathrm{R}$ & 1.3 & 2.8 & in & in & in & $401.6 \pm 9.9$ & in & in \\
\hline$\overline{\mathrm{J}}$ & 0.5 & 1.2 & in & in & in & $312.0 \pm 18.3$ & in & in \\
\hline $\mathrm{T}$ & 1.7 & 1.1 & in & in & in & $232.4 \pm 7.8$ & in & in \\
\hline Mel & & & & & & \pm 10.4 & & $0 \pm 2.3$ \\
\hline
\end{tabular}

in = inactive, $\mathrm{IC}_{50}>500 \mu \mathrm{g} / \mathrm{ml}$

$\mathrm{R}=$ Rianthong; $\mathrm{J}=\mathrm{Jumbo} ; \mathrm{T}=$ Taiwan; Mel = Melphalan 


\section{A. Apoptotic Cell Staining}

The apoptotic activity of the ethanolic extracts in Jurkat cells was observed and scored as morphological changes to the nuclei in the dead cells: chromatin condensation, nuclear-fragmentation, and appearance of apoptotic bodies (Fig. 1). The results showed that Rianthong extract induced the highest $\%$ of apoptotic cells among the jujube cultivars $(54.4 \pm 4.2 \%)$. The order of \% apoptotic Jurkat cells from high to low were melphalan $(70.7 \pm 4 \%)>$ Rianthong $(54.4 \pm$ $4.2 \%)>$ Taiwan $(45.0 \pm 4.6 \%)>$ Jumbo $(41.5 \pm 5.5 \%)$. The amount of apoptosis induced by the jujube seed ethanolic extracts were concentration-dependent (see Fig. 1).
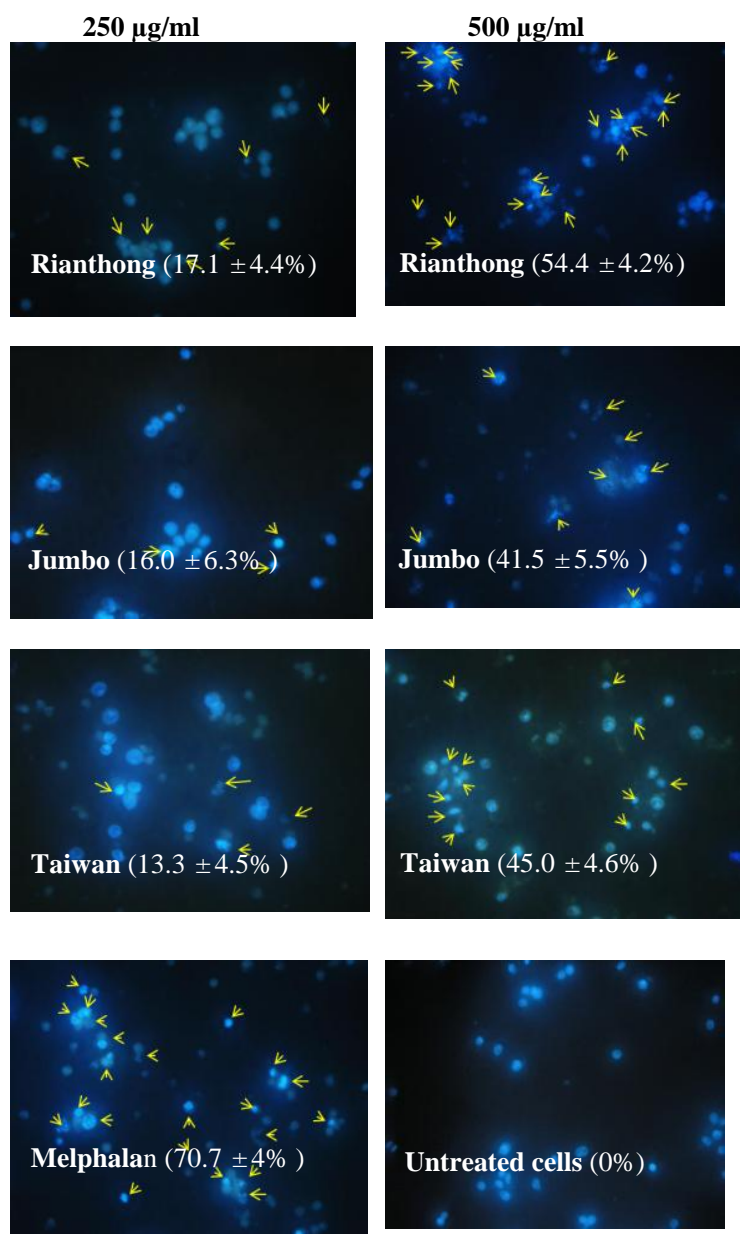

Fig. 1. Nuclei morphological changes and \%apoptotic Jurkat cells treated with jujube seed extracts at 250 and $500 \mu \mathrm{g} / \mathrm{ml}$ for $24 \mathrm{~h}(40 \times$ magnification $)$. Arrows indicate apoptotic nuclei.

\section{B. Detection of Induced Death Mode by Flow Cytometry}

Annexin V - FITC staining was used to differentiate apoptotic cell death from necrotic cell death. The increases in apoptotic cell death induced by the extracts and melphalan were both concentration- and time-dependent (Fig. 2). The ethanolic extract of Jumbo seed caused more apoptotic cell death (early and late stage) than other cultivars. However, more necrosis was observed at higher concentration and longer incubation times for all jujube extracts.

The ethanolic extracts, but not the water extracts, of the three jujube cultivar seeds showed potential anti-cancer activity in the Jurkat cell line based on antiproliferation and apoptosis induction effects. No cytotoxicity was observed in the HepG2 cancer cell line or the normal Vero cells. It should be noted that melphalan was cytotoxic in normal Vero cells. Cultivar Taiwan caused the most cell death in Jurkat cells as measured by NR assay (Taiwan > Jumbo > Rianthong). Additional study of the cancer death mode revealed that the ethanolic extracts from the three cultivars of jujube seed induced late stage apoptotic cell death after $24 \mathrm{~h}$ at both $1 \times \mathrm{IC}_{50}$ and $2 \times \mathrm{IC}_{50}$ concentrations. Jumbo induced the most late stage apoptosis (Jumbo > Rianthong > Taiwan > melphalan), while, Taiwan induced more undesirable necrotic cell death (Taiwan > Jumbo > Rianthong > melphalan). Taking the antiproliferation and apoptosis induction effect into consideration with necrotic effects, the ethanolic extract of Rianthong seeds showed the most potential as an anti-cancer therapeutic.

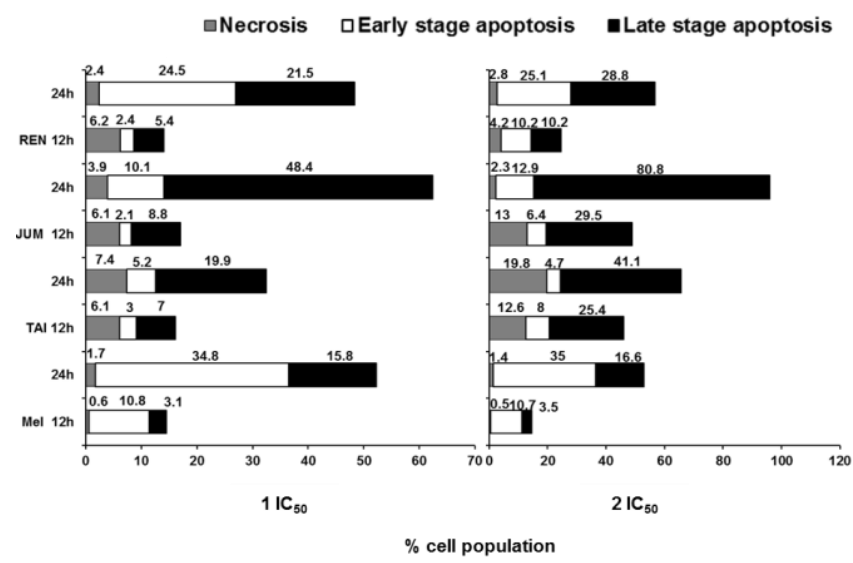

Fig. 2. \%Cell population of Jurkat cells treated with the jujube seed extracts at $1 \times$ IC50 and $2 \times$ IC50 concentrations for 12 and $24 \mathrm{~h}$.

Previous studies have shown Ziziphus species anti-cancer activity mediated via induction of apoptotic cell death in cancer cell lines [13]-[15]. The chloroform extract of $Z$. jujuba fruit has been reported to cause apoptosis induction effect against hepatocellular carcinoma cells (HepG2) [15], which is in contrast to our findings where both the water and ethanolic seed extracts of all jujube cultivars tested did not affect HepG2 cells. This suggests a different mechanism of anti-cancer activity in our jujube seed extracts, presumably due to the isolation of different active compounds by the different extraction methods. Another study showed that extracts from $Z$. jujuba fruit induced apoptosis in estrogen receptor alpha $(\mathrm{ER} \alpha)$ positive $(\mathrm{MCF}-7)$ and $\mathrm{ER} \alpha$ negative (SKBR3) breast cancer cells [14]. Similar to our study, the ethanolic extract from seed of $Z$. mauritiana was demonstrated to cause apoptotic cell death in human promyelocytic leukemia cells (HL-60), human acute lymphoblastic leukemia cells (Molt-4) and human cervical cancer cells (HeLa) without showing toxicity against normal human gingival fibroblast cells (HGF) [13].

\section{CONCLUSION}

Here we reveal that ethanolic extracts from seeds of three jujube cultivars selectively induce cytotoxicity in a human $\mathrm{T}$ cell leukemic cell line via the apoptosis pathway. The different abilities of the three jujube cultivars to induce apoptosis urges for further studies to define the bioactive components and to understand the therapeutic actions of 
these extracts.

\section{ACKNOWLEDGMENT}

This research study was financially supported by the Thai Research Fund (RDG5420072). The authors would like to thank the Center for Research and Development of Herbal Health Products (CRD-HHP), Khon Kaen University for facilities. The authors thank Dr. Glenn Neville Borlace for assistance with the English-language presentation.

\section{REFERENCES}

[1] J. T. Williams, "Introduction, Taxonomy, and History," in Friuts for the Future 2 (revised edition): Ber and other Jujubes, R. W. Smith, N. Haq, and Z. Dunsiger, Ed., Southampton, UK: International Centre for Underutilised Crops, 2006, ch. 1, pp. 1-17.

[2] J. W. Li, L. P. Fan, S. D. Ding, and X. L. Ding, "Nutritional composition of five cultivars of Chinese jujube," Food Chem., vol. 103 pp. 454-460, August 2006.

[3] Z. Shirdel, H. Madani, and R. Mirbadalzadeh, "Investigation into the hypoglycemic effect of hydroalcoholic extract of Ziziphus jujuba leaves on blood glucose and lipids in alloxan-induced diabetes in rats," IJDLD, vol. 8, pp. 13-19, March 2009.

[4] D. Dahiru, J. M Sini, and L. John-Africa, "Antidiarrhoeal activity of Ziziphus mauritiana root extract in rodents," Afr. J. Biotechnol., vol. 5, pp. 941-945, May 2006.

[5] D. Dahiru and O. Obidoa, "Pretreatment of albino rats with aqueous leaf extract of Ziziphus mauritiana protects against alcohol-induced liver damage," Trop. J. Pharm. Res., vol. 6, pp. 705-710, June 2007.

[6] K. K. Mishra, P. Kashyap, H. A. Sawarkar, B. P. Mule, S. K. Verma, and S. Kumar, "Evalution of antifungal activity of stones of Ziziphus jujube for ringworm infection," International Journal of Herbal Drug Research, vol. I, pp. 8-11, 2012.

[7] H. J. Heo, Y. J. Park, Y. M. Suh, S. J. Choi, M. J. Kim, H. Y. Cho, Y. J. Chang, B. Hong, H. K. Kim, E. Kim, C. J. Kim, B. G. Kim, and D. H. Shin, "Effect of oleamide on choline acetyltransferase and cognitive activities," Biosci. Biotechnol. Biochem., vol. 67, pp. 1284-1291, June 2003.

[8] W. H. Peng, M. T. Hsieh, Y. S. Lee, Y. C. Lin, and J. Liao, "Anxiolytic effect of seed of Ziziphus jujuba in mouse models of anxiety," $J$. Ethnopharmacol., vol. 72, pp. 435-441, April 2000.

[9] J. G. Eley and H. Dovlatabadi, "Permeability enhancement activity from Ziziphus jujuba," Pharm. Biol., vol. 40, pp. 149-153, October 2002.

[10] P. Panomwan and S. Sunit, "Triterpenes from the root of Thai Ziziphus Mauritiana," Journal of Science and Technology, Srinakharinwirot University, vol. 2, pp. 106-118, July-December 2001.

[11] H. L. Bai, J. Wang, C. M. Liu, and L. Li, "Isolation and purification of flavonoids from Ziziphus jujuba by high-speed counter-curren chromatography," J. Chin. Chem. Soc., vol. 57, pp. 1071-1076, July 2010.

[12] C. Bowe, "Composition," in Friuts for the Future 2 (revised edition): Ber and other Jujubes, R. W. Smith, N. Haq, and Z. Dunsiger, Ed., Southampton, UK: International Centre for Underutilised Crops, 2006 , ch. 2, pp. 18-23.

[13] T. Mishra, M. Khullar, and A. Bhatia, "Anticancer potential of aqueous ethanol seed extract of Ziziphus mauritiana against cancer cell lines and ehrlich ascites carcinoma," eCAM, vol. 2011, pp. 1-11, July 2010.

[14] P. Plastina, D. Bonofiglio, D. Vizza, A. Fazio, D. Rovito, C. Giordano, I. Barone, S. Catalano, and B. Gabriele, "Identification of bioactive constituents of Ziziphus jujube fruit extracts exerting antiproliferative and apoptotic effects in human breast cancer cells," $J$. Ethnopharmacol., vol. 140, pp. 325-332, January 2012.

[15] X. Huang, A. Kojima-Yuasa, T. Norikura, D. O. Kennedy, T. Hasuma, and I. Matsui-Yuasa, "Mechanism of the anti-cancer activity of Zizyphus jujuba in HepG2 cells," Am. J. Chinese Med., vol. 35, pp. 517-532, 2007.

[16] R. Siege, D. Naishadham, and A. Jemal, "Cancer statistics, 2012," CA. Cancer J. Clin., vol. 62, pp. 10-29, Jan. 2012.

[17] J. K. Brunelle and B. Zhang, "Apoptosis assays for quantifying the bioactivity of anticancer drug products," Drug Resist. Update, vol. 13, pp. 172-179, September 2010.

[18] F. H. Shirazi, N. Ahmadi, and M. Kamalinejad, "Evalution of northern Iran Menta pulegium L. cytotoxicity,” DARU, vol. 12, pp. 106-110, 2004.
[19] H. Babich and E. Bonrenfreund, "Cytotoxicity of T-2 toxin and its metabolites determined with the neutral red cell viability assay," Appl. Environ. Microb., vol. 57, pp. 2101-2103, July 1991.

[20] L. F. P. De Castro and M. Zacharias, "DAPI binding to the DNA minor groove: a continuum solvent analysis," J. Mol. Recognit., vol. 15, pp. 209-220, August 2002.

[21] S. Machana, N. Weerapreeyakul, S. Barusrux, A. Nonpunya, B. Sripanidkulchai, and T. Thitimetharoch, "Cytotoxic and apoptotic effects of six herbal plants against the human hepatocarcinoma (HepG2) cell line," Chin. Med., vol. 6, pp. 39, 2011.

[22] T. Nasri, R. R. Bosch, S. T. Voorde, and J. Fink-Gremmels, "Differential induction of apoptosis by type A and B trichothecenes in Jurkat T-lymphocytes," Toxicol. in Vitro, vol. 20, pp. 832-840, Febuary 2006.

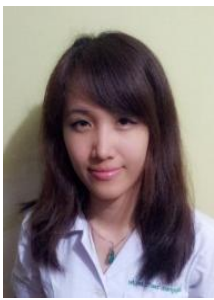

Natthanan Taechakulwanijya was born on 21st May 1989, Thailand. Currently she is studying Master degree, Pharmaceutical Chemistry and Natural Products, Khon Kaen, Thailand. She obtained her Bachelor of Applied Thai Traditional Medicine Thammasat University, Bangkok, Thailand in 2011 . She studied High school, Majoring in Science-Mathematics, Khon Kaen Demonstration school, Thailand in 2007.

From 2010 to 2011, she worked in Internships (Physical examination and treatment by, herbal massage, traditional Tha herbal studies, manufacturing system studies).

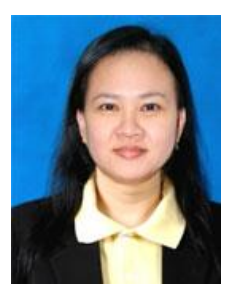

Natthida Weerapreeyakul is a Ph.D. Currently she is an associate professor in Department of Pharmaceutical Chemistry, Faculty of Pharmaceutical Sciences, Khon Kaen University, Khon Kaen, 40002, Thailand.

In 2001, she obtained her Ph.D. in Pharmaceutical Sciences, in University of Maryland, Baltimore, U.S.A In 1997, she received her M.Sc. in Medicinal Chemistry, in University of Illinois at Chicago, U.S.A. In 1991, she received her BSc in Pharmacy from Khon Kaen University, Thailand.

She has three recent publications : 1) S. Machana, N. Weerapreeyakul, S. Barusrux, K. Thumanu, and W. Tanthanuch, "FTIR microspectroscopy discriminates anticancer action on human leukemic cells by extracts of Pinus kesiya; Cratoxylum formosum ssp. pruniflorum and melphalan," Talanta, vol. 93, pp. 371-382, May 2012. 2) S. Machana, N. Weerapreeyakul, S. Barusrux, K. Thumanu, and W. Tanthanuch, "Synergistic anticancer effect of the extracts from Polyalthia evecta caused apoptosis in human hepatoma (HepG2) cells," Asian Pac. J. Trop. Biomed., vol. 2, pp. 589-596, August 2012. 3) S. Machana, N. Weerapreeyakul, S. Barusrux, A. Nonpunya, B. Sripanidkulchai, and T. Thitimetharoch, "Cytotoxic and apoptotic effects of six herbal plants against the human hepatocarcinoma (HepG2) cell line," Chin. Med., vol. 6, pp. 39, 2011

Her research interest includes Bioreduction/Cytotoxicity/Apoptosis induction/Alkylating activity, Biological activity for cosmeceutical product development, Prodrug design and development.

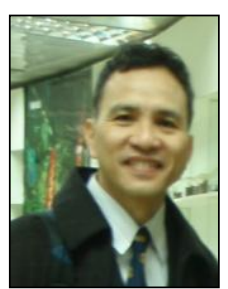

Sahapat Barusrux is a Ph.D. and an associate professor in Department of Clinical Immunology and Blood Bank, Faculty of Associated Medical Sciences, Khon Kaen University, Khon Kaen, 40002, Thailand. In 2003, he obtained his Ph.D. in Molecular Genetic \& Genetic Engineering from Mahidol University, Thailand. In 1991, he obtained his M.Sc. in Clinical Pathology from Mahidol University, Thailand. In 1985, he received his B.Sc. in Medical Technology from Khon Kaen University, Thailand.

He has three recent publications: 1) S. Machana, N. Weerapreeyakul, S. Barusrux, K. Thumanu, and W. Tanthanuch, " FTIR microspectroscopy discriminates anticancer action on human leukemic cells by extracts of Pinus kesiya; Cratoxylum formosum ssp. pruniflorum and melphalan," Talanta, vol. 93, pp. 371-382, May 2012. 2) S. Machana, N. Weerapreeyakul, S. Barusrux, K. Thumanu, and W. Tanthanuch, "Synergistic anticancer effect of the extracts from Polyalthia evecta caused apoptosis in human hepatoma (HepG2) cells," Asian Pac. J. Trop. Biomed., vol. 2, pp. 589-596, August 2012. 3) S. Machana, N. Weerapreeyakul, S. Barusrux, A. Nonpunya, B. Sripanidkulchai, and T. Thitimetharoch, "Cytotoxic and apoptotic effects of six herbal plants against the human hepatocarcinoma (HepG2) cell line," Chin. Med., vol. 6, pp. 39, 2011. 


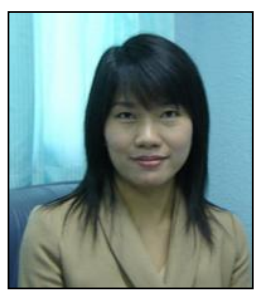

Sirithorn Siriamornpun is a Ph.D. and an associate professor in Department of Food Technology and Nutrition, Faculty of Technology, Mahasarakham University, Mahasarakham, 44150, Thailand.

In 2002, she received her Ph.D. in Food Science and Technology from University of New South Wales, Australia. In 1998, she obtained her M.Sc in Food Science and Technology from University of New South Wales, Australia. In 1994, she received her BSc in Food Science from Srinakharinwirot University, Thailand.

She has Three recent publications: 1) S. Siriamornpun, O. Kaisoon, and N.

Meeso, "Changes in colour, antioxidant activities and carotenoids (lycopene, $\beta$-carotene, lutein) of marigold flower (Tagetes erecta L.) resulting from different drying processes," J. Funct. Foods, vol. 4, pp. 757-766, October 2012. 2) J. Kubola, N. Meeso, and S. Siriamornpun, "Lycopene and beta carotene concentration in aril oil of gac (Momordica cochinchinensis Spreng) as influenced by aril-drying process and solvents extraction," Food Res. Int., vol. 50, pp. 664-669, March 2013. 3) J. Kubola, and S. Siriamornpun, "Phytochemicals and antioxidant activity of different fruit fractions (peel, pulp, aril and seed) of Thai gac (Momordica cochinchinensis Spreng)," Food Chem., vol. 127, pp. 1138-1145, August 2011.

Her research interest includes Bioactive compounds analysis, Development of functional food and nutraceutical products, Functional lipids. 